\title{
Thermal response of hands to computer work: comparison of three assessment procedures
}

\author{
Jan Horáček, Jan Novotný
}

Department of Kinesiology, Faculty of Sports Studies, Masaryk University, Brno, Czech Republic

\begin{abstract}
Introduction: Unlike other imaging modalities thermography is absolutely non-invasive and suitable to assess functional changes. However, in some fields, a methodology for its use has not even been set yet. This work compares three different methods to study the dynamics of skin temperature changes in hands during computer work. Methods: A total of 306 measurements of 20 office employees and 6 non-office employees was performed with a thermographic camera during a work shift. The thermograms were subsequently evaluated and three methodologies - regions of interest, two of them newly proposed $\mathrm{H} 2$ and $\mathrm{H} 5$ - were compared mathematically. In addition, two other methods were compared without mathematical confirmation. Results: The results shown the same tendencies of thermal changes comparing our methodologies with the methodology used earlier in more than $80 \%$ ( $88 \%$ in case of the first method, named $\mathrm{H} 2$ method and $85 \%$ in case of the second one, named H5). However, in comparison to an older procedure, our procedures have shown higher sensitivity to temperature changes in more than $60 \%$ of cases ( $61 \%$ in case of $\mathrm{H} 2$ and $68 \%$ in case of $\mathrm{H} 5)$. We measured a variation range difference of $1.6^{\circ} \mathrm{C}$, and, with the $\mathrm{H} 5$ method, the whole $2.1^{\circ} \mathrm{C}$ compared to the method used earlier. Conclusion: This work has determined a new procedure for measuring of dynamics of hands temperature changes, which is not only easier and faster to perform and evaluate, but it is also more capable of detecting temperature changes on hands.
\end{abstract}

Keywords: hands, thermography methods, computer work

\section{INTRODUCTION}

In various economic sectors, employees have been using a personal computer as a primary work tool (usually equipped with a keyboard and computer mouse) for approximately thirty years. Many of them experienced some musculoskeletal problems such as forearms tendinitis, carpal tunnel syndrome etc. These problems cause an increase in the number of days spent away from work and the related economic loss. In 2016, they made up for the whole $19.8 \%$ of all causes of sick leaves among employees in the Czech Republic. Therefore, they were the second most frequent cause of sick leaves right after airway respiratory tract diseases. On average, the period of this leave stretched to 65.7 days (Ústav zdravotnických informací a statistiky ČR, 2017). The actual prevalence of pain localized in upper limbs, but not causing incapacity for work, was set by Andersen et al. (Andersen, Haahr, \& Frost, 2007) to approximately 11-28 \% of all employees and services. The relationship between personal computer use and musculoskeletal problems in upper limbs has already been proved many times (Gerr, Monteilh, \& Marcus, 2006). The same applies to the relationship between musculoskeletal problems and temperature of hands (Gold, Cherniack, Hanlon, Dennerlein, \& Dropkin, 2009; Novotný, 2009).

Despite the fact that thermographic cameras have been used in medicine since the 1960s, (Ring \& Ammer, 2000; Ammer, 2008) and since 1990s many scientific papers have been published about "progress of thermal imaging technology" (Ring, 1990), still, in some fields of thermography, no significant research has been conducted. This unsatisfactory state was evaluated directly 
by Ring and Ammer in 2006 (F. Ring \& Ammer, 2006), when they wrote that infra-red imaging "is often misunderstood or not been used due to lack of knowledge of thermal physiology". Seixas et al. commented on the problems almost identically in 2014 (Seixas, Vardasca, Gabriel, \& VilasBoas, 2014) more than twenty years after the topic was published for the first time (Sharma, Smith, Hazleman, \& Jenner, 1997).

The first study dealing with the relationship between the temperature of hands and computer work was written by Sharma et al. in 1997 (Sharma et al., 1997). They used their own methodology on how to measure and evaluate temperatures. From now on only two or three methods have been introduced so far. However, no work dealing with the methodology alone was published since.

According to our findings, confirmed by Seixas and Rodrigues in their review (Seixas \& Rodrigues, 2016), only five works focusing on computer work-related thermal changes in hands have been published so far (Gold, Cherniack, \& Buchholz, 2004; Gold et al., 2009; Gold, Cherniack, Hanlon, \& Soller, 2010; Reste et al., 2015; Sharma et al., 1997).

These five works, however, written by only three authors (Sharma et al., Reste et al. and Gold et al.), present us only three used methods. All of them focus on the dorsal side of the hands. All authors explain why their method is the very best one. But none of them provides a comparison with other authors. They also do not explain why they haven't chosen any other - not so good method. All the methods are charted in Fig. 1.

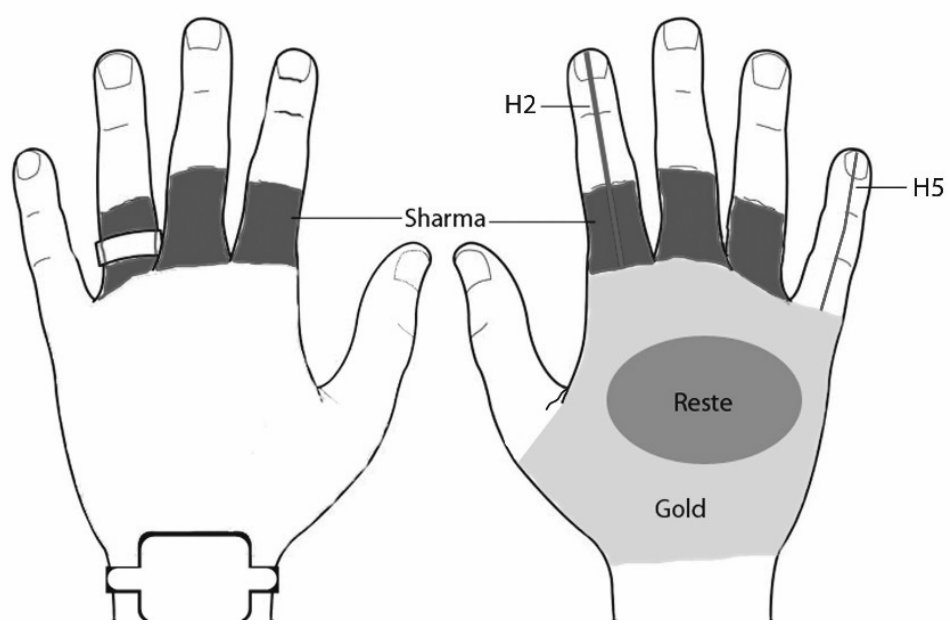

Fig 1: Regions of interest in accordance with Sharma, Reste, Gold and Author ( $\mathrm{H} 2$ and $\mathrm{H} 5)$.

Sharma used "over 200-350 pixels on the 2nd, 3rd, and 4th proximal phalanges of both hands"(Sharma et al., 1997).

With the utmost probability, Gold performed all measurements in all her researches using the same method. She measured the average temperature of the metacarpal region of the dorsal right hand. This region was demarcated by heads of ulna and radius and with metacarpal joints (Gold et al., 2004, 2009, 2010). She explained that this area is the most reliable location for detecting vascular response and abnormality in the hand (Stansberry et al., 1999; Gold et al., 2004).

Reste used her own research method. As we can see at her figures, she measured the mean temperature in an ellipsoid area placed it in the middle of the metacarpal region without more accurate localization (Reste et al., 2015).

The method used by Sharma et al. has several limitations such as the problematic feasibility and significant amount of time required without the utilization of specialized localization software. We have also considered the imaging of proximal phalanx of the 4th finger to be very problema- 
tic because in many cultures over the world, it is reserved for a wedding ring as well as the 3rd finger, on which rings are often worn for different, less frequent reasons. If the researcher wanted to compare both hands for any reason, gathering data would either be very difficult/inaccurate, or it would not meet the conditions of the natural environment. The same applies if the people wearing rings would be asked to remove them. Also, we believe that there may be some changes in blood circulation in a finger, on which a ring is worn in the long term, but they are not yet scientifically confirmed.

The region of interest chosen by Reste was found by us to be very similar to Gold's methodology. Unlike Gold's it wasn't sufficiently defined and so it has also been excluded from the comparison.

Hypothesis made by Gold regarding the suitability of hand dorsum was built on the findings of Stansberry et al. (Stansberry et al., 1999), who has described the back of the hand showing significant differences in vessel vasodilation during different kinds of induction. All of this was done without any comparison to any other, similarly hairy regions of the hand. The method introduced by Gold, even though it would correspond to our requirements regarding sensitivity and specificity to changes of perfusion of the hand with blood, did not correspond to our requirements of simplicity and time required to data analysis. Manual delimitation of the monitored region in thermographic software was very laborious, especially in case of larger files. Also, in the pilot study (Horáček \& Novotný, 2017), we have discovered that during field measurements, in which we strive for the highest possible authenticity, large wristwatch of several measured people interfered with the measured region, which distorted results and made delimitation of the monitored region even more difficult.

None of the presented methods met our expectations regarding speed and ease of use (Sharma and Gold), and, at the same time, the accuracy of localization (Reste). This led to the creation of our own methods and to a subsequent comparison.

As we can see from the arguments, from all the methods used hitherto, only the method by Gold was left as a reference for comparison with our regions of interest. One of the reasons for this was also often proven the ability of Gold's method to detect specific pathologies in upper limbs (Gold et al., 2004, 2009).

The aim of this work was to find the most suitable method - region of interest (ROI) - for scanning of temperature changes on the hands of subjects working on the computer. Specifically, to find a method, which would be not only sufficient but also simple and fast to evaluate. Among other requirements belonged its usability outside of laboratory conditions, and, last but not least, possible larger sensitivity to thermal changes and probably related pathological changes, described by Gold et al. (Gold et al., 2009).

\section{METHODS}

The Thermographic Imaging in Sports and Exercise Medicine checklist (TISEM) (Moreira et al., 2017) recommendations were followed during data collection, data analysis and data reporting. Before taking thermograms, all participants signed written informed consent after explained the goals and procedures of the study. Whole research was approved by the ethical committee for research of our university following the Declaration of Helsinki.

\section{Participants}

For our study volunteered 26 participants. 20 of them working primarily on a personal computer and 6 using computer merely superficially but also using their hands as a working tool. All of them were white, ethnic Czechs. The distribution of sex was 21 women and 5 men. The aver- 
age age at the time of measuring was 34,3 years with a standard deviation of 11,1 years. There were 22 right-handed people and 4 left-handed people among the participants. But only one of them used a left-handed computer mouse at work. Three of them were smokers. One man and two women. Three participants reported upper limb symptoms (such as pain, burning, tingling etc.) at the time of assessment, 9 reported recent symptoms but not in a day of assessment and 14 participants did not report any symptoms.

As we can see from the description of the measured persons, the group was significantly heterogeneous in age, sex, occupation and all other factors. As we did not investigate the similarity of subjects or their thermal response to stress, but the similarity of thermal dynamics in ROIs it did not cause any problem. These ROIs were the same with all the participants as well as the procedure of measurements and data analysis.

\section{Regions of interest}

During selection of a more suitable location for temperature monitoring, we followed findings of Stansberry et al. (Stansberry et al., 1999) about better suitability of the hairy part of the hand, and also from findings of Mercer and Weerd (Mercer \& Weerd L, 2005). In accordance with them, blood serves as the primary carrier of heat in the body (therefore in hands as well), its perfusion is controlled by vascular tonus and hand temperature is therefore mostly determined by blood flow and rather insignificantly by muscular metabolism.

At the same time, we attempted to satisfy our requirement regarding simplicity of ROI determination. The mean temperature of a line leading through the centre of a finger was chosen. The line was led from the most distal part of a finger (including the nail part) to the base of proximal phalanx on the dorsal side of a finger. If necessary (especially in case of index fingers), the line was adjusted to always pass through the centre of a finger. With regard to the findings of Gold (Gold, 2002) concerning finger temperature being less constant than hand dorsum temperature, more significant temperature fluctuations were expected. For our interest in work with the computer, we assumed that on a keyboard both hands are loaded approximately the same. The difference is on a dominant - usually right - hand using a computer mouse, where usually index finger is loaded specifically by "clicking" and therefore there is the possibility of the larger response to stress. For this reason, the right-hand index finger (and the left-hand index finger, for control and on behalf of the left-handed people) was selected. This region was designated H2. Even thou that working on the personal computer doesn't mean just "clicking”. Still right (or left) index finger is in some way specifically involved in this work. Differently than the fifth finger for sure. For this reason, we have selected the same region on the fifth finger of both right and left hand. Our assumption was that the little finger will not be stressed using a computer mouse in contrast to the index finger. This region was designated $\mathrm{H} 5$. Analogically, the area of hand dorsum in accordance with Gold was shortly named $\mathrm{G}$ in charts and graphs. Another reason for choosing second and fifth fingers was that usually on these fingers there are no rings or other jewellery which could interfere with reading.

\section{Methodological procedures}

Standard conditions for thermal imaging have been defined earlier (E. F. Ring, 1990; Ammer, 2008; Ammer \& Ring, 2013; Moreira et al., 2017). Except for the conditions which could, or even had to be adhered to, such as the perpendicular and consistent distance of the imaging device and the measured subject, some conditions could not be adhered to because of logical reasons in this field measuring. To satisfy the requirement of measuring under real conditions, the actual measuring was performed from the beginning of a work shift to its end. During this shift, we simply could not prohibit our subjects to use restrooms and probably also to smoke and drink coffee at work. Because of this, we had to exclude some recommendations of paragraph 2) of 
TISEM. Specifically avoiding caffeine, large meals, smoking and showering for four hours before the assessment. In the end, most problems were caused by using of toilet, specifically by washing hands after its use between measuring sessions. This was the cause of the largest number of missing thermograms, because the surface of hands cooled significantly after washing and it took a couple of minutes (approximately 5-10) before restoration of the original temperature occurred (question remains, to what extent was the restoration even possible and what was the impact of washing in comparison to the impact of change of activity performed with hands). As we wanted to measure under real conditions, we also didn't order measured subjects to take off any rings, wristwatches or other jewellery. All other recommendations were followed.

Nevertheless, the goal of our work was not to measure specific temperatures or their dynamics but the difference between three ROIs, so any possible temperature differences made by caffeine, nicotine or food did not interfere with our measurements as far as we measured all three ROIs under the same conditions. All extrinsic factors affecting skin temperature (e.g. massage, heat or cold exposure etc.) were avoided.

The exact measuring time differed significantly, because most employees got to work at different times and left at different times. However, the period of measuring always corresponded with the morning shift. Therefore, approximately from 7-8 o'clock to lunch, or several hours after lunch. Prior to every measuring, thermal acclimatization of the measured subjects to the work environment took place. During the acclimatization, they have read, they have been explained and they have signed the informed consent with the research, and they have also filled in the worklist, into which they have entered their initials and other required information. This always took approximately 15 minutes. As far as all person spend their work shift in the same place, no other acclimatization was needed for any other measurements that day. The introductory measuring followed. All other measurements took place every other half-an-hour. Always on the hour and on the half hour, within five minutes interval - depending on the ability to interrupt the given activity. Regarding the varying time of arrival to the place of employment, lunch break and/or going home, we have performed a total of 306 measuring sessions of 26 subjects.

With office employees, the measuring took place in their offices. In the case of physical therapists, it took place in the emergency rehabilitation gym. Since the measuring sessions took place during four different days, the measuring conditions were slightly different but rather consistent during the whole period of measuring. These were performed in the period from June to August. The mean temperature was $25.7^{\circ} \mathrm{C}$ with a standard deviation of $1.7^{\circ} \mathrm{C}$ and the average relative humidity was $46.1 \%$ with a standard deviation of $4.7 \%$. All four days were rainless and higher than average in terms of temperature. All places where measuring took a place were without air conditioning.

All thermograms were taken using FLIR P660 camera (NETD $<45 \mathrm{mK}$ and sensor array size of $640 \times 480$ pixels) with emissivity setting of 0.98 . Before every measurement camera was turned on and it was waited few seconds until "calibrating" disappeared from the display. During a measurement, camera was held perpendicularly to the hand in approximately $80 \mathrm{~cm}$ above a table so both hands lying next to each other with spread fingers took about $80 \%$ of thermogram. The measured person was sitting behind a table with hands flexed in elbows to right angle. Hand was held slightly above a table.

After measurement thermograms were processed in ThermaCAM ${ }^{\mathrm{TM}}$ Researcher Pro 2.10, FLIR. At figure 2, thermogram with marked ROIs in accordance with Gold is to be seen. It is interfered with by a wristwatch and with four $\mathrm{H}$ lines on the 2 nd and 5 th finger. The measured person does have a ring on the third finger of their left hand, but it does not interfere with any of the measured areas. On the thermogram, we can also see a slight adjustment of the $\mathrm{H} 2$ line because of the unevenness of the measured finger. All the acquired data were subsequently processed in Excel ${ }^{\circledR}$ (Microsoft ${ }^{\circledR}$ Office Professional Plus 2016, version nr. 1809). STATISTICA (Dell, version 12) software was used for statistical analysis. 


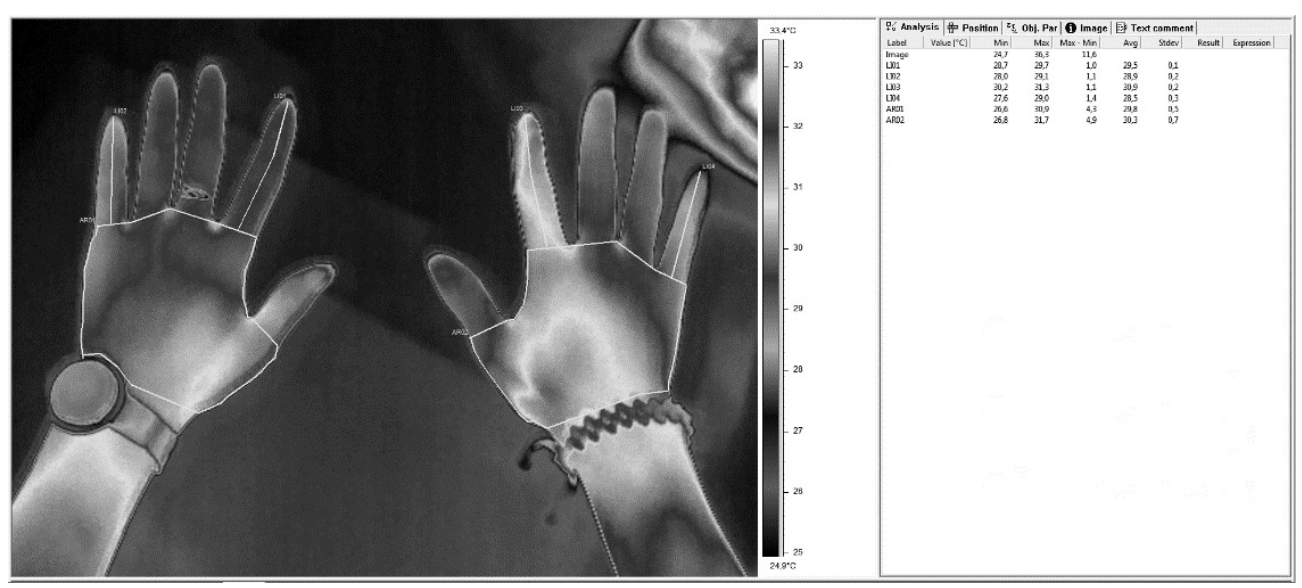

Fig. 2: One thermogram, processed in ThermaCAM ${ }^{T M}$ Researcher Pro 2.10, FLIR. More detailed description in the text.

\section{Data analysis}

For statistical processing, all the data were entered into charts with a strict time range of 30 minutes. In 29 cases the data were missing due to a technical problem or an absence of the employee at his or her workplace. In case of these missing data, the temperatures were calculated as an arithmetic average of the neighbouring temperatures

For the graphic representation, we have used a rainbow palette with an attached heat scale as recommended for use in medicine by Ring and Ammer. (Ring \& Ammer, 2012)

Considering that Gold et al. method is an accepted methodology when analyzing hand temperature changes, it was used as a reference standard to compare the results of the two newly proposed methods.

Several operations were performed to mathematically confirm some aspects of similarity of our method with the method of Gold. At first, all the temperatures were entered into a chart calculator and thermal curves for measured persons during the entire day were created. One of these curves is to be seen at Figure 3. In the right side of the graph, there is an hour-long lunch break to be seen. 


\section{Participant 23}

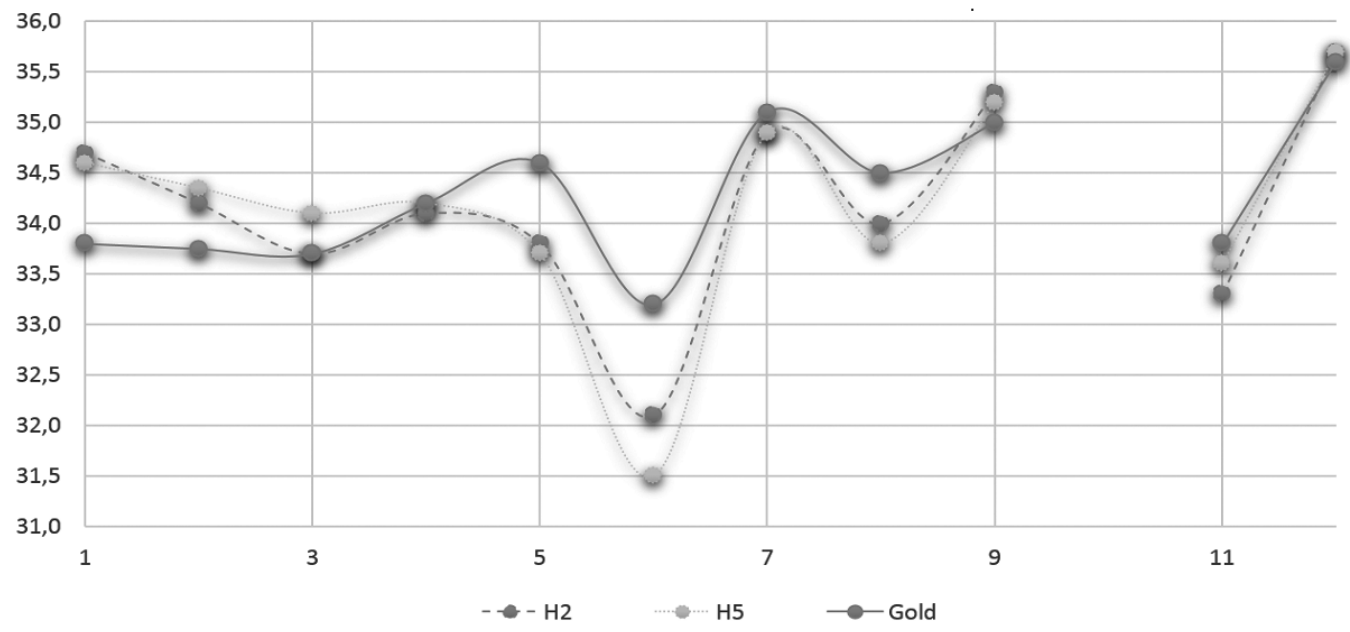

Fig. 3: Graphics processing of a thermogram of participant 23. On the $X$-axis, the elapsed time from the initial measuring in minutes can be seen, on the $\mathrm{Y}$-axis, the temperature in ${ }^{\circ} \mathrm{C}$ can be seen. The curves represent thermal changes in the right hand of the participant 23 and their mutual relationships.

Mean temperatures of $\mathrm{H} 2, \mathrm{H} 5$ and dorsal area of Gold were calculated as the first mathematical operation. Then we performed a matrix matching of all the measured temperatures with evaluation of the warmest region during all measurements.

The next mathematical operation was performed to confirm the same temperature tendencies (to confirm if the curves are similar or not). Only two options were allowed. It is, or it is not the same. The temperature is increasing or decreasing. Therefore, we were trying to find out, whether the cooling or warming occurs in all measured regions identically. During this calculation, the value of the earlier temperature $T_{1}$ was subtracted from the following temperature, $T_{2}$, as can be seen at Figure 4. This applies not only to both our methods but also to the method of Gold. These two (three) results were multiplied by each other. This formula was used:

$$
\mathrm{X}=\left(\mathrm{T}_{2 \mathrm{H}}-\mathrm{T}_{1 \mathrm{H}}\right) *\left(\mathrm{~T}_{2 \mathrm{G}}-\mathrm{T}_{1 \mathrm{G}}\right) \text {. }
$$

If the sign of the final number was positive, it meant that the temperature tendencies were the same. If it was negative, the tendencies were different. The final of 0 pointed to zero change of one of the temperatures and the accord or discord of temperature curves had to be completed (corrected) manually after an optical evaluation of the graph regarding a larger period of time. 


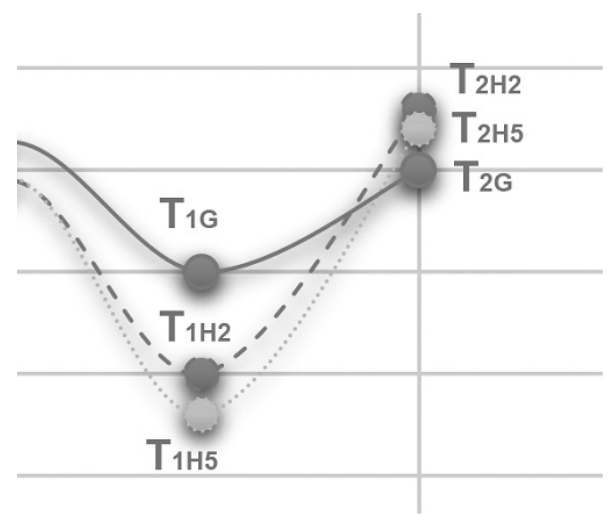

Fig. 4: Graphic representation of temperature reading on a cut-out of one of the thermograms.

On every curve, we can see temperature $\mathrm{T} 1$ on the left and temperature $\mathrm{T} 2$ on the right.

During the comparison of the following temperature section, $\mathrm{T} 2$ is marked $\mathrm{T} 1$ and the $\mathrm{T}_{2}$ marking is transferred to the next value.

After mathematical calculation of temperature tendencies, and therefore specificity with a reference to Gold, we have performed mathematical description of sizes of curves amplitudes and therefore, the sensitivity of the method to any pathologies or ongoing phenomena. This was achieved in two ways. First by variation range of measured temperatures of every subject for all methods.

The second approach to the comparison of temperature amplitudes was the comparison of areas under the curve by subtraction of the integrals of temperature changes between all measuring sessions. For this, we used formula:

$$
Y=\left|T_{2 H}-T_{1 H}\right|-\left|T_{2 G}-T_{1 G}\right|
$$

Once again, if the final number was positive, the $\mathrm{H}$ method had a larger temperature difference (either to higher or lower temperatures). If the number was negative, it was the method of Gold, which was the more sensitive one. Resulting 0 pointed on the same deviation, which was a good result for the methods we have selected because their processing was significantly easier and faster while achieving the same, previously confirmed results. Therefore, the confirmation of the result being identical to the result of Gold is also positive, even though we did not consider it in that manner in terms of statistical importance.

Subsequently, differences between $\mathrm{H} 2$ and $\mathrm{H} 5$ methods were evaluated in accordance with the aforementioned procedures.

At the end, the conformity (tendencies/directions of thermal curves) of office workers and non-office workers for all three ROIs were compared to check if our methodology works not only for office workers but also for people doing other than computer work. The same mathematical method as was used for comparing thermal curves before was applied.

\section{RESULTS}

Both of our methods for evaluation of temperatures on hands during work on the computer were found to be significantly simpler and faster to perform without the use of a special software than the method used by Gold.

After the temperatures have been entered into the graphs it was seen that the resulting curves of Gold and both $\mathrm{H}$ methods are very similar (Fig. 3). 
The different amplitudes and different temperature levels, through which the curves run, are a visually significant phenomenon. The following results were acquired by mathematical processing:

\section{Mean temperature}

During the whole period of measuring, mean temperatures of the monitored regions were, in descending order, $33.9^{\circ} \mathrm{C}$ in the region of Gold, $33.8^{\circ} \mathrm{C}$ in the dorsum of the second finger $(\mathrm{H} 2)$ and $33.5^{\circ} \mathrm{C}$ in the dorsum of fifth finger (H5). However, during a comparison of the frequency of the warmest and the coldest region, the results were different. Most often, the warmest part of the hand was the dorsum of the right index finger $(\mathrm{H} 2)$ in 287 cases $(42 \%)$, subsequently hand dorsum of Gold in 275 cases ( $40 \%$ ) and lastly the dorsum of the little finger in 121 cases (18 \%).

\section{Dynamics}

During comparison to curves of Gold, prior to manual correction, an $80 \%$ match was identified in $\mathrm{H} 2$ curves (444 cases from 554), $10 \%$ were in opposite direction and in $10 \%$ of cases, the direction of one of them was horizontal and the match, therefore, could not be determined mathematically. After the manual correction, the match was identified in $88 \%$ of cases ( 486 out of 554 cases) and only $12 \%$ had the opposite tendency. In the case of the H5 curves, the situation was very similar in comparison to the temperature curves of Gold. Prior to correction, there was $79 \%$ of matching tendencies ( 437 out of 554 cases), $13 \%$ with the opposite directions and $8 \%$ with no way to determine tendency. After correction, there was $85 \%$ of matching tendencies (470 out of 554 cases) in contrast to $15 \%$ in the opposite direction. The results of the comparison of temperature trends are clearly summarized in tab. 1.

Tab. 1: The counts of matching and opposite time temperature trends in the $\mathrm{H} 2$ and $\mathrm{H} 5$ methods in comparison to the method of Gold and to each other (after correction)

\begin{tabular}{|l|c|c|}
\hline Compared methods & Ratio of trend conformity (\%) & Ratio of trend difference (\%) \\
\hline H2 vs. Gold & $486(88 \%)$ & $68(12 \%)$ \\
\hline H5 vs. Gold & $470(85 \%)$ & $84(15 \%)$ \\
\hline H2 vs. H5 & $530(96 \%)$ & $24(4 \%)$ \\
\hline
\end{tabular}

\section{Amplitude}

The mean variation range was determined by a comparison of variation ranges - in the descending order, it constituted $5.8{ }^{\circ} \mathrm{C}$ in the $\mathrm{H} 5$ method, $5.3{ }^{\circ} \mathrm{C}$ in the $\mathrm{H} 2$ method and $3.7{ }^{\circ} \mathrm{C}$ in hand dorsum by Gold. The results of comparison absolute values of mean temperatures are clearly summarized in tab. 2.

Tab. 2: Absolute values of mean temperatures in the $\mathrm{H} 2$ and $\mathrm{H} 5$ in comparison to the method of Gold

\begin{tabular}{|l|c|c|c|c|}
\hline Methodology & $\begin{array}{c}\text { Mean temperature } \\
\left({ }^{\circ} \mathbf{C}\right)\end{array}$ & $\begin{array}{c}\text { Standard deviation } \\
\left({ }^{\circ} \mathbf{C}\right)\end{array}$ & $\begin{array}{c}\text { Variation range } \\
\left({ }^{\circ} \mathbf{C}\right)\end{array}$ & $\begin{array}{c}\text { Difference } \\
\text { to Gold }\left({ }^{\circ} \mathbf{C}\right)\end{array}$ \\
\hline Gold & 33.9 & 1.3 & 3.7 & \\
\hline H2 & 33.8 & 2.0 & 5.3 & 1.6 \\
\hline H5 & 33.5 & 2.0 & 5.8 & 2.1 \\
\hline
\end{tabular}

By comparing the amount of temperature change in every period against the method of Gold, in case of $\mathrm{H} 2$ method, we have discovered a larger deviation in $61 \%$ of cases (340 out of 554 cases), in $9 \%$ of cases, the change was of similar size and in $30 \%$ of cases, the region in accordance with Gold had larger thermal response to stress. In case of H5 method, the change in tem- 
perature was higher in $68 \%$ of cases ( 379 cases out of 554), similar to Gold in $9 \%$, and in $22 \%$ of cases, the change was larger in Gold. The results of the comparison of temperature changes are accurately summarized in table 3 .

Tab. 3: Amounts of larger, same and lower temperature differences in the $\mathrm{H} 2$ and $\mathrm{H} 5$ methods in comparison to the method of Gold and to each other

\begin{tabular}{|l|c|c|c|}
\hline \multicolumn{4}{|c|}{ Temperature changes } \\
\hline & H$^{*}>$ Gold & H $^{*}=$ Gold & H $^{*}$ Gold \\
\hline H2 vs. Gold & $340(61 \%)$ & $50(9 \%)$ & $164(30 \%)$ \\
\hline H5 vs. Gold & $379(68 \%)$ & $51(9 \%)$ & $124(22 \%)$ \\
\hline H2 vs. H5 & $158(29 \%)$ & $83(15 \%)$ & $313(56 \%)$ \\
\hline
\end{tabular}

\section{Dynamics for office and non-office workers}

It was found that while for a whole group of 26 subjects the conformity of $\mathrm{H} 2$ curves to curves of Gold was $80 \%$ before correction ( 444 cases out of 554) the conformity for office workers was 81 $\%$ ( 319 out of 394 ) and for the non-office worker $78 \%$ ( 125 out of 160 cases). For H5 method the results were very similar. Conformity for the whole group was $79 \%$ (437 out of 554 cases) while for office workers only was $78 \%$ (309 out of 394 cases) and for non-office workers $80 \%$ (128 out of 160). As can be seen, the difference is only $2 \%$ for both groups of office and non-office workers. The results are summarized in table 4.

Tab. 4: Ratio of trend conformity before manual correction

\begin{tabular}{|l|c|c|}
\hline \multicolumn{3}{|c|}{ Ratio of trend conformity (\%) } \\
\hline & H2 vs. Gold & H5 vs. Gold \\
\hline For whole group & $\mathbf{8 0}$ & $\mathbf{7 8}$ \\
\hline For office workers & 81 & 78 \\
\hline For non-office workers & 78 & 80 \\
\hline
\end{tabular}

\section{DISCUSSION}

The fact that both methods proposed by us (even as a whole, i.e. both used together) are significantly easier, faster and so cheaper to perform in comparison to the method recommended by Gold is not to be found in the result and it is also very hard to be measured. Our results point out that both our methods are capable of recording of thermal changes on the surface of hands with higher amplitude during work than methods of Gold (as seen in table 2).

One can agree with Gold et al. that the increase in temperature of hands while using a personal computer cannot be done by the production of heat by these muscles (Gold et al., 2004). However, it is necessary to question if the participating muscles can influence the resulting temperature in a different manner. For example, as a heat accumulator, which would either slow down the temperature change or even decrease it. The reason, why during the comparison of current temperatures of Gold, $\mathrm{H} 2$ and $\mathrm{H} 5$ regions did the $\mathrm{H} 2$ regions come out as the warmest, followed by the region selected by Gold and lastly the $\mathrm{H} 5$ region, remains a question. There can be plenty of mechanisms causing this phenomenon.

When comparing with thermal curves of the Gold's method, the tendencies of $\mathrm{H} 2$ method came out as $1 \%$ (before correction), respectively $3 \%$ (after correction) more similar than the H5 method (as seen in table 1). Regarding the amplitude of thermal change, the H5 method came 
out as having higher amplitudes in the whole $7 \%$ than the $\mathrm{H} 2$ method in comparison to Gold's method (as seen in table 3). In absolute numbers, this difference between $\mathrm{H} 2$ and $\mathrm{H} 5$ was $0.5^{\circ} \mathrm{C}$ (seen in table 2). It is a question whether this difference of half a degree can relevantly affect the sensitivity of the method, regardless of what should be diagnosed using this method. If we consider the method of Gold to be capable of diagnosing musculoskeletal problems (Gold et al., 2004 ) in upper limbs with range of $3.7^{\circ} \mathrm{C}$ (as seen in table 2), we say that the $\mathrm{H} 5$ method with a range of $5.8{ }^{\circ} \mathrm{C}$ is more sensitive and thus could be a better method for the price of losing only 12 , respectively $15 \%$ of curve shape. All of this regarding the fact that the difference of $15 \%$ from the shape of curves of Gold points out just their difference but not lower specificity in the representation of pathological processes. Since this work only compares the consistency of two methods, it is well possible that this $15 \%$ difference stands for $15 \%$ increased accuracy. This would have to be proven by another more statistical study. The fact that the temperature range of hand surface of some subjects consisted of $2-3{ }^{\circ} \mathrm{C}$ during the whole shift also reflects the importance of this temperature difference. Theoretically, in case of some measured people, emphasizing the measured results by $2.1{ }^{\circ} \mathrm{C}$ could create a difference of up to $100 \%$.

For further research, it might be interesting to consider the temperature differences of the index finger (H2) and the little finger (H5) in employees using primarily a computer mouse. This comparison could be performed both regarding employees using primarily a keyboard or a different control element of the computer and regarding employees working in a different field (drivers, tradesmen etc.).

These differences, though they look promising and suggest bigger suitability of H5 method before the Gold's one, require further research. This research would prove whether the discovered difference stands for higher or lower specificity of these methods to the detection of musculoskeletal problems already proven by Gold and her team.

\section{CONCLUSION}

Computer work-related musculoskeletal disorders are widespread nowadays and the use of thermal imaging devices to detect them has many advantages. However, only small progress on this field was made in recent years. This paper shows a possibly better way how to measure thermal dynamics on hands. All of this by comparing newly proposed regions of interest to already published ones. These regions of interest were measured in real conditions out of the laboratory.

The newly proposed $\mathrm{H} 2$ and $\mathrm{H} 5$ regions of interest for monitoring of hand surface temperature were compared to the known and verified one of Gold.

In comparison with this method, both newly proposed methods were found to be capable of measure the same dynamics in more than $85 \%$. In contrast to the method of Gold, the results suggested the ability to measure higher fluctuation of temperature in more than $61 \%$, the actual difference being up to whole $2.1^{\circ} \mathrm{C}$.

In addition, both new methods were found to be significantly simpler and easier to perform. However, that was not measured and thus cannot be supported statistically.

Although this paper is presenting in our opinion a better way to measure temperature changes on hands still there are many other ways how it could be done which needs to be scientifically proven to be better or worse. From this point of view, this work just shows the work which still must be done to fully appreciate the value of thermography in clinical practise. 


\section{Acknowledgements}

This project was supported by the Ministry of Education, Youth and Sports of the Czech Republic (ROZV/25/FSpS/03/2017 - Thermography of hands stressed by work on the computer with mouse - ID 37347).

\section{References}

Ammer, K. (2008). The Glamorgan Protocol for recording and evaluation of thermal images of the human body (Vol. 18).

Ammer, K., \& Ring, E. F. (2013). Standard Procedures for Infrared Imaging in Medicine. In Medical infrared imaging: principles and practices. Boca Raton, FL: CRC Press/Taylor \& Francis.

Andersen, J. H., Haahr, J. P., \& Frost, P. (2007). Risk factors for more severe regional musculoskeletal symptoms: a two-year prospective study of a general working population. Arthritis and Rheumatism, 56(4), 1355-1364.

Gerr, F., Monteilh, C. P., \& Marcus, M. (2006). Keyboard use and musculoskeletal outcomes among computer users. Journal of Occupational Rehabilitation, 16(3), 265-277.

Gold, J. E. (2002). Indicators of upper extremity musculoskeletal disorders: Digital vibration threshold testing and infrared thermography. University of Massachusetts Lowell.

Gold, J. E., Cherniack, M., \& Buchholz, B. (2004). Infrared thermography for examination of skin temperature in the dorsal hand of office workers. European Journal of Applied Physiology, 93(1-2), 245-251.

Gold, J. E., Cherniack, M., Hanlon, A., Dennerlein, J. T., \& Dropkin, J. (2009). Skin temperature in the dorsal hand of office workers and severity of upper extremity musculoskeletal disorders. International Archives of Occupational and Environmental Health, 82(10), 1281-1292.

Gold, J. E., Cherniack, M., Hanlon, A., \& Soller, B. (2010). Skin temperature and muscle blood volume changes in the hand after typing. International Journal of Industrial Ergonomics, 40(2), 161-164.

Horáček, J., \& Novotný, J. (2017). How hard is work with personal computer and how to measure it - Thermographic methods. Not new, but still just promising. Presented at the 11 th International Conference on Kinanthropology'Sport and Quality of Life', Brno.

Mercer, J., \& Weerd L., de. (2005). The effect of water-filtered infrared-A (WIRA) irradiation on skin temperature and skin blood flow as evaluated by infrared thermography and scanning laser Doppler imaging (Vol. 15).

Moreira, D. G., Costello, J. T., Brito, C. J., Adamczyk, J. G., Ammer, K., Bach, A. J. E., ... Sillero-Quintana, M. (2017). Thermographic imaging in sports and exercise medicine: A Delphi study and consensus statement on the measurement of human skin temperature. Journal of Thermal Biology, 69, 155-162. https://doi.org/10.1016/j.jtherbio.2017.07.006.

Novotný, J. (2009). Využití termografie pro sportovce. Studia sportiva, 3(1).

Reste, J., Zvagule, T., Kurjane, N., Martinsone, Z., Martinsone, I., Seile, A., \& Vanadzins, I. (2015). Wrist Hypothermia Related to Continuous Work with a Computer Mouse: A Digital Infrared Imaging Pilot Study. International Journal of Environmental Research and Public Health, 12(8), 9265-9281.

Ring, E. F. (1990). Quantitative thermal imaging. Clinical Physics and Physiological Measurement: An Official Journal of the Hospital Physicists' Association, 11 Suppl A, 87-95.

Ring, E. F. J., \& Ammer, K. (2000). The Technique of Infra red Imaging in Medicine (Vol. 10).

Ring, E. F. J., \& Ammer, K. (2012). Infrared thermal imaging in medicine. Physiological Measurement, 33(3), R33-46.

Ring, F., \& Ammer, K. (2006). Thermal Imaging in Diseases of the Skeletal and Neuromuscular Systems. In Electrical Engineering Handbook. Medical Devices and Systems (Vols 1-3, pp. 31-1-31-15). CRC Press.

Seixas, A., \& Rodrigues, S. (2016). Dynamics of skin surface temperature in the hand after computer work: A review. In Occupational Safety and Hygiene IV (Vols 1-0, pp. 287-291). CRC Press.

Seixas, A., Vardasca, R., Gabriel, J., \& Vilas-Boas, J. (2014). Recent application of infrared thermography in work-related musculoskeletal disorders. In P. Arezes, J. Baptista, M. Barroso, P. Carneiro, P. Cordeiro, N. Costa, ... G. Perestrelo (Eds.), Occupational Safety and Hygiene II (pp. 737-741). CRC Press.

Sharma, S. D., Smith, E. M., Hazleman, B. L., \& Jenner, J. R. (1997). Thermographic changes in keyboard operators with chronic forearm pain. BMJ : British Medical Journal, 314(7074), 118.

Stansberry, K. B., Peppard, H. R., Babyak, L. M., Popp, G., McNitt, P., \& Vinik, A. (1999). Primary nociceptive afferents mediate the blood flow dysfunction in non-glabrous (hairy) skin of type 2 diabetes: A new model for the pathogenesis of microvascular dysfunction. Diabetes Care; Alexandria, 22(9), 1549-1554.

Ústav zdravotnických informací a statistiky ČR. (2017). Ukončené prípady pracovní neschopnosti pro nemoc a úraz 2016. 


\section{Corresponding author:}

\section{Jan HORÁČEK}

Department of Kinesiology

Faculty of Sports Studies

Masaryk University

Kamenice 5

Brno-Bohunice 62500

Czech Republic

e-mail: horacek.ja@seznam.cz 